Acknowledgements

We thank M.W,

Lazar for excellent

photography and s.

Jordan-Williams for

typing assistance
1. Yunis, J.J. \& Prakash O. Science 215, 15251530 (1982)

2. Sibley C.G. \& Ahlquist J.E. J. molec. Evol. 20,215 (1984)

3. DeGrouchy J. Genetica 73, 37-52 (1987).

4. Wienberg J., Jauch A., Stanyon R. \& Cremer T. Genomics 8, 347-350 (1990).

5. Baldini A. et al. Chromosoma 101, 109-114 (1991).
6. Ijdo J.W., Baldini A., Ward D.C., Reeders S.T. \& Weils R.A. Proc. natn. Acad. Sci. U.S.A. 88 9051-9055 (1991).

7. Jorgensen A.L., Laursen H.B., Jones C. \& Bak A.L. Proc. natn. Acad Sci. U.S.A. 89, 33103314 (1992).

8. LalleyP.A.etal. Cytogenet. Cell Genet. 51,503532 (1989).

9. Verma R.S. \& Babu A. Human Chromosomes:
Manual of Basic Techniques. (Pergamon Press New York, 52-54 1989).

10. Pinkel D. et al. Proc. natn. Acad. Sci. U.S.A. 85 9138-9142 (1988).

11. Lichter P.etal. Hum. Genet 80, 224-234 (1988).

12. An International System for Human Cytogenetic Nomerclature: Birth defects original article series Vol. 21, 1. (The National Foundation, New York, 1985).

\section{Schizophrenia scepticism}

Sir-Jones and colleagues ${ }^{1}$ report an alanine to valine substitution in codon 713 of the amyloid precursor protein gene $(A P P)$ in a single case of chronic schizophrenia. They were unable to detect this mutation in a further 100 unrelated patients with schizophrenia as well as in 105 individuals with obtained when the data from this marker were analysed according to a range of genetic models. Individuals with RDC diagnoses of schizophrenia $(n=69)$, schizoaffective disorder $(n=$ $10)$ and unspecified functional psychosis $(n=6)$ were scored as affected. Overall, there was no determined by the codon 713 variant ${ }^{1}$ or by other mutations in the $A P P$ gene. If this mutation is indeed pathogenic, it must be an extremely rare cause of schizophrenia. Although mutations within the APP gene can lead to a spectrum of different phenotypes ${ }^{3}$, these all involve the abnormal deposition of $\beta$ amyloid. In the absence of evidence that this is a neuropathological feature of

\begin{tabular}{|c|c|c|c|c|c|c|c|c|c|c|c|}
\hline \multicolumn{12}{|c|}{ Lod scores from two-point analysis of D215210 data under four different genetic models } \\
\hline & & Penetrances & & Frequency of & & & Lod score & at $\theta=$ & & & \\
\hline Model & $\mathrm{A} 1 \mathrm{~A} 1$ & $\mathrm{~A} 1 \mathrm{~A} 2$ & A2A2 & A2 & 0.0 & 0.01 & 0.05 & 0.1 & 0.2 & 0.3 & 0.4 \\
\hline 1 & 0.001 & 0.95 & 0.99 & 0.02 & -12.50 & -9.40 & -5.49 & -3.32 & -1.19 & -0.36 & -0.09 \\
\hline 2 & 0.002 & 0.087 & 1.0 & 0.064 & -4.64 & -4.10 & -2.60 & -1.51 & -0.45 & -0.10 & -0.02 \\
\hline 3 & 0.0 & 0.061 & 0.656 & 0.04 & -4.20 & -3.51 & -1.94 & 0.95 & -0.13 & -0.06 & -0.03 \\
\hline 4 & 0.0 & 0.00 & 1.0 & 0.10 & - & -14.94 & -7.00 & -3.76 & -1.20 & -0.34 & -0.07 \\
\hline
\end{tabular}

A2 is assumed to be the mutant allele. Intermediate models ( $2 \& 3$ ) assume a population risk of $1 \%$ and are compatible with published recurrence risks in relatives ${ }^{4}$.

presenile dementia and 100 nondemented controls. Nevertheless, they suggest that its position in a highly conserved portion of the APP gene suggests that it may prove to be pathogenic.

We have been studying the cosegregation of highly polymorphic microsatellite markers on chromosome 21 in 191 individuals from 24 families containing multiple cases of schizophrenia and related disorders. Eight of these families are from South Wales, 13 from South East England and 2 from Japan (ref. 2). Amongst the markers we have studied is 21-GT 12 (D21S210) which is located close to the APP gene. The table shows the two-point lod scores evidence for linkage to this locus in these families nor was there any evidence for heterogeneity (the sum of all positive lod scores at $\theta=0$ was $<3$ for all four models).

Three of the families showed modestly positive lod scores with this marker $(0.32<\mathrm{Z}>0.78)$, but single strand conformation analysis (SSCA) of exon 17 of the APP gene in individuals with schizophrenia from each of these families failed to detect any abnormality. We have also screened 58 unrelated individuals for mutations in exon 17 of APP using SSCA and detected no abnormality.

We therefore conclude that susceptibility to schizophrenia in our multiply affected families is not schizophrenia we remain sceptical that mutations in APP cause the disorder.

\section{R. Mant}

P. Asherson

M. Gill

P. McGuffin

M. Owen

University of Wales College of Medicine, Department of Psychological Medicine, Heath Park, Cardiff CF4 4XN,

Wales, UK

\section{References}

1. Jones, C.T. et al. Nature Genet. 1, 306-309 (1992).

2. Gill, M. et al. Psychological Medicine (in the press)

3. Hardy, J. A. Nature Genet. 1, 233-234 (1992)

4. McGuffin, P. et al. Psychological Medicine 13, 31-43 (1983). 